\title{
Life Challenges and Mental Health Issues of Single Mothers: A Systematic Examination
}

\author{
Siti Marziah Zakaria, Nor Hazila Mat Lazim, Suzana Mohd. Hoesni
}

\begin{abstract}
${ }^{1}$ Abstract: As the number of single mothers worldwide increases, their challenges and health issues were discussed in the previous literature. This systematic analysis aims to reveal mental health problems of single-mothers and discuss the adversities faced by them. Financial hardship was seemingly the most significant problem among the low incomes, unemployed and poor single mothers, which showed that poverty and mental health problems were inextricably related. Several factors were found in this study, which has led the single mothers to poverty, such as lowincome employment, large numbers of self-employment, unemployed, low education level, lack of adequate skills and age factor. In addition to that, numerous lines of research have indicated that low social support from the surrounding area was the factor of the distress of single mothers. Previous studies showed that single mothers use negative coping strategies, for example, consuming drugs, cigarettes, alcohol, and antidepressants to alleviate the effects of stressful life. These coping strategies were found to be harmful to their physical and mental health. Therefore, suggestions and recommendations are provided to improve the lives of single mothers and their children to accomplish quality of life.
\end{abstract}

Index Terms: Mental Health, Single Mother, Systematic Analysis, Well-Being

\section{INTRODUCTION}

Over the last few decades, family patterns have changed and the number of single-parent households around the globe was increasing, mainly led by women. According to the census, the total number of people with depression was estimated to exceed 300 million in 2015, equivalent to $4.4 \%$ of the world population [1]. Meanwhile, by 2020, depression alone was predicted to be the second highest cause of disease load worldwide with $(5.1 \%)$ of women that were more likely to experience mental health problems than men with (3.6\%) [1][3]. In addition to that, studies have proven that many of these women were mothers [4].

Single mothers refer to a person who is widowed, single unwed mothers, separated or divorced, and unmarried women who adopted children [5][6]. However, the definition of single mothers has been developed to include a woman

Revised Manuscript Received on September 25, 2019

Siti Marziah Zakaria, Centre of Psychology and Human Development, National University of Malaysia (UKM), Bangi, Malaysia.

Nor Hazila Mat Lazim, Faculty of Language and Linguistics, University of Malaya (UM), Kuala Lumpur, Malaysia.

Suzana Mohd Hoesni, Centre of Psychology and Human Development, UKM, Bangi, Malaysia. who is the breadwinner and caregiver in the family due to husband ill health, disability or substance and alcohol misuse, followed by a woman abandoned by her husband and is taking care of the children without the support from the husband, a woman in the divorce process in which the husband did not provide the financial help and other forms of support for their children and lastly, a woman who is taking care of other people's children without the support from the husband [7] [8].

These single mothers were categorized as a vulnerable group that were at risk of poor physical health such as, debilitating chronic illness, poor mental and social health with few supportive social contexts. Based on the poverty dimension in Malaysia, single mothers were classified as poor, including the indigenous people and minority groups, agricultural workers, particularly challenged people and the elderly [9] and their status and function were profoundly similar to the rest of the population [10]. Thus, this systematic review aims to: a) exploring life challenges faced by single mothers b) identify mental health issues among single-mothers worldwide, and c) evaluating available support systems for single mothers.

\section{METHOD}

This article employs systematic review to analyze findings of past research on mental health issues among single mothers. It will provide an overview of the findings and identify any remaining gaps in knowledge. A comprehensive search has been conducted to find relevant articles. Keywords used are: single mother, mental health issues, challenges and support systems. The articles are based on research in psychology and social work which employs quantitative design. A number of fifty articles have been accumulated and analyzed. Eventually, this paper managed to cite 41 articles from 50 collected articles. The sample, methodology, analysis, and findings of research have been examined and summarized.

The inclusion criteria for the articles to be selected are: articles published in 2000-2018, refereed and indexed articles only, the sample must be single mothers, and the sampling 
method must be random sampling. This procedure will provide a complete and exhaustive summary of current evidence relevant to the research objectives. The data has been extracted from included studies. The risk of bias has also been evaluated. The result of this systematic review will be presented in the next section: results and discussion. The recommendation for practice will also be provided in the last section before summary. Future directions for research to fill existing gaps in knowledge and to strengthen the body of evidence will be suggested in summary section.

\section{RESULTS AND DISCUSSION}

\section{A. Life Challenges of Single-mothers}

Life as a single mother is often associated with difficulties, challenges, and high demands. Several common challenges were faced by single mothers involving in financial problems, role or task overload problems (such as coordinating childcare and balancing work, child and household responsibilities), social life, problems with exspouse, and other idiosyncratic problems such as, health concerns, and behavioural problems [11]. However, from the previous studies, have found that financial or economic problems of single mothers was the most vital concern and presumably to have financial hardship as married mothers [12] [13] [14] [15] followed by emotional and psychological problems, family problems and stigma and community support problems [16].

Nevertheless, financial difficulties were determined by mortgage or rent arrears, debt and lack of savings as well as having no money to buy food and fuel [17]. On the contrary, a study reported different findings in which depressive symptoms were more prevalent in households headed by single mothers whose age between 2550 years, and demonstrated that economic difficulties and low social support were not correlated with the depressive symptoms in the family [18].

In addition, a considerable amount of literature has shown the connection between mental health and poverty, which showed that people in lower socio-economic groups had experienced higher rates of psychiatric problems than those in higher socio-economic groups [10]. Researchers have elaborated that single mothers with lowincome have higher psychiatric disorders than higher income single mothers, with $19 \%$ and $15 \%$ respectively. These single breadwinners were also less likely to be employed than married mothers.

Besides, low monthly revenues had an impact on the psychological well-being of single mothers and children in rural and urban areas [19].
Apparently, they have felt sense of loss, helplessness, anxiety, guilt and anger when they were unable to provide their children with sufficient attention, affection and basic needs in the absence of a father in the household and had to struggle working more extended hours in order to make ends meet [20]. This has led to a significantly higher stress level for single mothers than married mothers [15].

In general, several factors such as low-income employment, a large number of self-employment, unemployed, low levels of education, insufficient skills and age have caused single mothers to poverty [21]. Poverty among the single mothers in Malaysia was caused by high levels of dependency, working in informal jobs that do not generate high income, unemployed, having no part-time job, unhealthy, and having low education achievement [9]. Research also stated that more than two-thirds of their participants lived under the poverty line and about $78 \%$ were unemployed [26].

Meanwhile, American and European women with past experiences of single motherhood were younger and had a lower income and wealth, were less likely to be married as older adults compared with married mothers [22]. It can be concluded that it is significant to the single mothers to be employed with rewarding income and steadying economic resources. Previous studies have shown that employed single mothers who were happier and had functioned relatively well were also less likely to experience psychological distress [23] [24].

Several lines of research have indicated that social support from the surrounding area was the determinant of the distress of single mothers. Social support has been referred to one's social bonds, social integration, and primary group relationships [25]. It can be indicated by the types of support such as social activities, personal talks, parental feedbacks, providing money or material goods, and assisting with childcare [26]. It has been suggested that social support is significant as an individual felt loved, appreciated and felt secured to rely on others and thus, lower the psychological distress of an individual [25].

In Canada and Australia, single mothers have reported lower levels of perceived social support, social involvement and frequent contact with friends and family than married mothers [27]. However, single mothers/woman in Scandinavian countries, namely Denmark, Sweden, Norway as well as Malaysia were mainly satisfied with the social support from their family members, friends, and relatives [13] [16] [28] [29]. Apart from that, confidant support was a significant predictor in the single mother group 
compared with the non-single mother group [13].

Several studies have focused on the emotional effects of separation between mother and children [26] [30]. A study conducted by other researchers also demonstrated that $68 \%$ of mothers were permanently separated from their children at birth or before the children reached 18 years old [30]. As a result, the mothers had no attachment with their children after separation. Studies showed that parents had lost custody due to the risk of harm, neglect, and physical abuse. Besides losing contact with their children, women have also experienced the loss of close friends and relatives during relapses and had difficulty relying on someone to take care of their children [31] [32].

In addition, problems with alcohol consumption and daily smoking were more prevalent among single mothers who were depressed [15] [18]. The use of alcohol was highly associated to the emotional factor and women began to use alcohol as a way to escape negative emotions and other related complex problems such as loneliness, unresolved conflicts with ex-spouses, divorce, or spousal death [15]. Meanwhile, studies showed that single mothers had attempted to escape from the problems by consuming alcohol and anti-depressants to alleviate their stressful life [31].

Compared to partnered mothers, single mothers were highly related to heavy smoking, which indicates that they smoke as a mean to deal with negative thoughts.

Although single mothers have faced great challenges and demands, they have undeniably become better with specific skills. A longitudinal study has found that single parents have good parenting skills, good family management, good communication skills, growing personally and providing financial support [34]. Parental skills involve being supportive of children, helping children to cope, and fostering independence. The strengths of family management were wellorganized, dependable, and efficient schedules. They also have good communication skills, including building a sense of honesty and trust. Their personal growth was widely associated with the sense of success and positive attitude.

Other study found that maternal optimism was a positive resource, predicting lower levels of maternal internalising symptoms and higher levels of effective child management [35]. It moderates the impact of economic stress on maternal internalising problems. On the contrary, single mothers were reported to feel positive about themselves as they were more efficacious than inefficacious, more positive than negative, more valued than disvalued but restricted and burdened by motherhood [36]. The majority of single mothers remained single and not remarried because they were concerned about the wellbeing of the children and decided not to be involved in a romantic relationship which may be stigmatized by their family or community [11]

\section{B. Mental Health Issues of Single-mothers}

The concept of mental health was referred to "subjective well-being, perceived self-efficacy, autonomy, competence, intergenerational dependence, and self-actualization of one's intellectual and emotional potential, among others" [3]. People with mental health problems can be categorized into three groups; (1) first group included those with acute mental health problems such as, normal depression and other stressful event, (2) second group referred to those with mental health that was more severe in chronic conditions but can maintain normal functioning, and (3) in third group were those with severe, chronic mental diseases that can influenced functional disability [37].

From a well-being perspective, life as a single mother has been related to higher levels of chronic stress, mental disorder, episodes of depression, lower satisfaction and happiness in life, more negative life events and many childhood adversities than married mothers [13] [23] [26] [27]. Particularly, study found that single mother had an increase chance of an anxiety disorder, depression, dysthymia, generalized anxiety disorder (GAD), post-traumatic stress disorder, and antisocial personality disorder compared to married mothers [38]. Other mental health problems are bipolar disorder, schizophrenia, or schizophrenia-related disorder for example, schizoaffective or schizophreniform for more than a year [26]. As a result of mental health problems, single mothers were likely to be prevented from undertaking specific tasks. They have also reported to have low selfconfidence to take on new challenges [10].

On the other hand, studies found that women who have experienced single motherhood between the ages 16 and 49 were at risk of physical disability and poor health in later life [22] and this association was the highest in the US, England, Denmark and Sweden. Poor mental health has also contributed to poor physical health such as obesity, hypertension, poor general health, and back pain [39] [40]. A report revealed that only $13.5 \%$ of mothers have reported having poor physical health, while $60.9 \%$ reported being in good health [26]. This clearly showed that poor mental health often leads to physical health problems and is an important risk factor for a range of health problems. 
The nurturing and nursing capability was significantly affected by mental health problems, medication, and relapses among mothers [26] [30]. Previous researches have indicated that pregnancy and childbirth were associated with a higher risk of mental health problems such as post-partum depression. For example, a finding has shown that $13 \%$ of women were at risk for post-partum depression and this was related to predictors like prenatal depression, childcare stress, life stress, prenatal anxiety, low social support, maternity blues, history of depression, and unplanned or unwanted pregnancy [41]. As a result, the quality of life of single mothers and their daily functioning were negatively affected [42] [43]. They may also have significant bonding problems with infants [44].

Previous studies have established that children of single-mothers were more likely to experience emotional or behavioural problems [36] [45] [46] [47]. For instance, researchers revealed that most children with mother that has a severe mental illness such as depression or bipolar disorder often have risks, which led to severe injuries to parents or family members, having trouble with the law, and suffering abuse, neglect, or parental addictions. In addition, children were reported to have behaviour problems due to the increase of depressive symptoms of mothers, and the children were likely to have recurrent death or suicidal thoughts similar to their mothers [47].

Studies have also found that women with psychotic disorders were at higher risk of fetal death or stillbirth due to a combination of genetic, antenatal and obstetric factors [46]. Moreover, children with single mothers have also suffered from poor mental and physical health due to socio-economic factors. German crosssectional survey [48] showed that male children living with single mothers were often obese, while female children from single mothers have higher chances of asthma, and both of male and female children were at risk to develop mental health problems. Therefore, it can be concluded that the mental health of mothers is an important public health issue due to its association with the physical and mental health of the children.

\section{Support Systems for Single-mothers}

The phenomenon of the single mothers is no longer a personal issue but has become a social problem and a public issue. Previous studies have shown that single mothers received two types of support which are formal and informal [29]. This was due to the fact that it was impossible for a single mother to simultaneously play a dual role as provider and nurturer without any support systems.

Informal support system refers to social and family support in the neighborhoods. An informal support system can increase the sense of emotional well-being of single women and mothers, and subsequently help to improve to their socio-economic well-being [29]. Informal support was found to be helpful in improving and protecting mental health through multiple ways by reducing vulnerability of individuals to psychosocial stressors, increasing the likelihood of adopting positive health-related social norms (i.e. regular physical activity), and uplifting self-esteem, self-sufficiency and self-efficacy [49].

Apart from that, formal support systems consisted of government agencies, welfare institutions and community networks, individuals, experts, as well as online counselling services. Certain formal support systems have provided support, social networking, advice, contacts, information about the availability of skills training and encouragement to single mothers [28]. Comprehensive mental health studies should be conducted on an ongoing basis that can improve physical health, increase productivity, improve relationships, lower substance abuse rates, and improve community safety for the single mothers [50].

In Malaysia, single mothers have been involved in entrepreneurship because of pushing and pulling factors such as to fulfil basic needs, government incentives, and demographic factors [21]. The desire to change the social and economic status of the family is the dominant factor that motivate women to engage in business. Nevertheless, some of them have experienced failure in conducting business due to limited training in entrepreneurship skills, limited capital support, family conflicts, and health problems. Therefore, past studies have suggested the need for a more gendersensitive governmental policy and practice. There is a need for additional programs to support families and mothers with depression. They should also have a better access to mental health resources [47].

\section{IMPLICATION AND RECOMMENDATION}

In precise, single mothers deserve better attention and intervention as well as treatment in order to improve their physical and psychological well-being, economic and social outcomes. There are few ways to make life easier for stressed single mothers, which are: medical and professional assistance in case of depression or psychological disorders, stress management plan such as deep breathing and a quick 10 minutes' hot shower, and experts advice for financial issues to alleviate stress and burden. Proper diagnosis, assistance, treatment and medication will significantly improve many areas of life including parenting skills and coping strategies.

Despite the challenges and opportunities, mental health systems have been overlooked by single-mothers and children. This situation is unfortunate; thus the effective service models can be extremely helpful to the families with mental illness. Therefore, psychologists could play their main role in the provision of these services. In addition, existing evidence have shown that single mothers were more likely to utilize mental health services for mental and emotional problems than married mothers. Since the prevalence of single motherhood was increasing throughout the world, social policies that protect women in vulnerable family situations can help in improving the population health and reducing mental health challenges. 


\section{CONCLUSION}

In conclusion, evaluating the adversities and analyzing the mental health problems of single mothers can be helpful in the development of sustainable family policies and service systems that are required to promote women mental health. Financial hardship is the most fundamental adversities faced by single mothers. Therefore, to overcome this problem, formal support system such as the government agencies, welfare institutions, community networks, and experts should play their role to alleviate poverty among single mothers. On the other hand, social and family support should be improved to reduce psychological distress, stress, and depression and to let the single mothers feel loved, valued, and cared.

\section{ACKNOWLEDGEMENT}

This article has been written based on a research grant funded by UKM. The research code is GGPM-2017-128. Special thanks to FSSK, CRIM, and PSITRA for continuous support and encouragement.

\section{REFERENCES}

1. World Health Organization (WHO). (2017). Depression and Other Common Mental Disorders. Geneva: World Health Organization.

2. World Health Organization (WHO). (2000). Women's Mental Health: An Evidence Based Review. Geneva: World Health Organization.

3. World Health Organization (WHO). (2001). Mental Health: New Understanding, New Hope. Geneva: World Health Organization.

4. Nicholson, J., Biebel, K., Hinden B., Henry, A., \& Stier, L. (2001). Critical Issues for Parents with Mental Illness and their Families. Worcester, MA: Center for Mental Health Services Research, Department of Psychiatry, University of Massachusetts Medical School.

5. Hew, C.S. (2003). The Impact of Urbanization on Family Structure: The Experience of Sarawak, Malaysia. SOJOURN, 18(1), 89-109.

6. Subramaniam, M., Prasad, R. O., Abdin, E., Vaingankar, J. A., \& Chong, S. A. (2014). Single mothers have a higher risk of mood disorders. Annals of the Academy of Medicine, Singapore, 43(3), 145151

7. Evans, M. (2011). Single Mothers in Malaysia: Social Protection as an Exercise of Definition in Search of Solution. International Conference of "Social Protection for Social Justice" Institute of Development Studies, UK

8. M. Bakri, M. (2002). Malaysia in the era of globalization. Lincoln: Writer's Club Press Rohaty.

9. Nor Aini, I., \& Selvaratnam, D. P. (2012). Program pembasmian kemiskinan dalam kalangan ibu tunggal: Analisis penyertaan dan keberkesanan. Prosiding Perkem, 1, 248-259.

10. Jayakody, R., \& Stauffer, D. (2000). Mental health problems among single mothers: Implications for work and welfare reform. Journal of Social Issues, 56(4), 617-634.

11. Karupiah, P. (2016). Marital status and the influence of emphasized femininity on the romantic relationships of tamil single mothers in Malaysia. Contemporary Perspectives in Family Research, 10, 375393. https://doi.org/10.1108/S1530-353520160000010015.

12. Intan Hashimah, M.H., Azman Azwan, A., \& Noraida, E. (2015) Stress, Roles and Responsibilities of Single Mothers in Malaysia. SHS $\begin{array}{llll}\text { Web of Conferences, } 18 & \text { (3), } 1-7 . & \text { https://doi.org/ }\end{array}$ $10.1051 /$ shsconf $/ 20151803003$.

13. Bull, T., \& Mittelmark, M. B. (2009). Work life and mental wellbeing of single and non-single working mothers in Scandinavia. Scandinavia Journal of Public Health, 37, 562-568. https://doi.org/10.1177/1403494809340494

14. Kotwal, N., \& Prabhakar, B. (2009). Problems Faced by Single Mothers. Journal of Social Sciences, 21(3), 197-204. https://doi.org/10.1080/09718923.2009.11892771

15. Kim, G. E., Choi, H., \& Kim, E. (2018). Impact of economic problems on depression in single mothers: A comparative study with married women. PLoS ONE, 13(8), 1-14. https://doi. org/10.1371/journal.pone.0203004.

16. Faizah, G., \& Hazirah, H. (2013). Challenges and Locus Control among Single Mothers in Muar. Journal of Emerging Trends in Educational Research and Policy Studies, 4(5), 760-765.

17. Stack, R. J., \& Meredith, A. (2018). The Impact of Financial Hardship on Single Parents: An Exploration of the Journey from Social Distress to Seeking Help. Journal of Family and Economic Issues, 39 (2), 233 242. https://doi.org/10.1007/s10834-017-9551-6.

18. Wang, J.L. (2004). The difference between single and married mothers in the 12-month prevalence of major depressive syndrome, associated factors and mental health service utilization. Soc Psychiatry Epidemiology, 39, 26-32. https://doi.org/10.1007/s00127-004-0699-7

19. Nurliza, A., Khadijah, A., Arena, C.K., \& Chong, S.T (2015). Psychological Well-Being among Single Mothers of Rural and Urban Areas in Selangor. International Journal of Technical Research and Applications, 25(25), 43-46.

20. Siti Rafiah, A.H., \& Sakinah, S. (2013). Exploring Single Parenting Process in Malaysia: Issues and Coping Strategies. Procedia - Social and Behavioral Sciences, 84, 1154-1159. https://doi.org/10.1016/j.sbspro.2013.06.718

21. Rohayu, R., Noor Sharipah, S. S., Yusmarwati, Y., Maziana, M., \& Abdul Rasid, A. R. (2000). Poverty Alleviation among Single MotheriIn Malaysia: Building Entrepreneurship Capacity. International Journal of Business and Social Science, 2 (17), 92-99.

22. Berkman, L. F., Zheng, Y., Glymour, M. M., Avendano, M., Börschsupan, A., \& Sabbath, E. L. (2015). Mothering alone: cross-national comparisons of later-life disability and health among women who were single mothers. Journal Epidemiol Community Health, 69(9), 865-872. https://doi.org/10.1136/jech-2014-205149

23. Meier, A., Musick, K., Flood, S., \& Dunifon, R. (2016). Mothering Experiences: How Single Parenthood and Employment Structure the Emotional Valence of Parenting. Demography, 53(3), 649-674. https://doi.org/10.1007/s13524-016-0474-x.

24. Turner, H. A. (2007). The significance of employment for chronic stress and psychological distress among rural single mothers. American Journal of Community Psychology, 40(3-4), 181-193. https://doi.org/10.1007/s10464-007-9141-0.

25. Turney, R. J., \& Brown, R.L. (2010). Social Support and Mental Health. In Scheid, T. L., \& Brown, T. N (Eds.) A Handbook for the Study of Mental Health. Cambridge: Cambridge University Press. Second Edition

26. Mowbray, C., Schwartz, S., Bybee, D., Spang, J., Rueda-Riedle, A., \& Oyserman, D. (2000). Mothers with a Mental Illness: Stressors and Resources for Parenting and Living. Families in Society: The Journal of Contemporary Social Services, 81(2), 118-129. https://doi.org/10.1606/1044-3894.1006

27. Crosier, T., Butterworth, P., \& Rodgers, B. (2007). Mental health problems among single and partnered mothers: The role of financial hardship and social support. Social Psychiatry and Psychiatric Epidemiology, 42(1), 6-13. https://doi.org/10.1007/s00127-006-01254.

28. Dayang Suria, M. (2017). Survival Strategies of Single Mothers among Indigenous Ethnics in Rural Areas: Case Study in Kota Belud, Sabah. Jurnal Kinabalu, 23, 43-64.

29. Noraida, E., Azman Azwan, A, \& Intan Hashimah, M.H. (2015). Formal and Informal Support Systems for Single Women and Single Mothers in Malaysia. SHS Web of Conferences, 18.

30. Dipple H, Smith S, Andrews H, Evans B. (2002). The experience of moth- erhood in women with illness. Soc Psychiatry Epidemiol, 37, 336-340.

31. Mullick M, Miller LJ, \& Jacobsen T. (2001). Insight into mental illness and child maltreatment risk among mothers with major psychiatric disorders. Psychiatry. Serv. 52: 488-492.

32. Blegen, N. E., Hummelvoll, J.K., \& Sverinsson, E. (2010). Mothers with mental health problems: A systematic review. Nursing and Health Sciences, 12, 519-528.

33. Sperlich, S., \& Maina, M. N. (2014). Are single mothers' higher smoking rates mediated by dysfunctional coping styles? BMC Women's Health, 14(1), 1-7. https://doi.org/10.1186/1472-6874-14 124

34. Richards, L.N., \& Schmiege, C.J. (1993). Problems and Strengths of Single-Parent Families: Implications for Practice and Policy. Family Relations, 42 (3), 277-285.

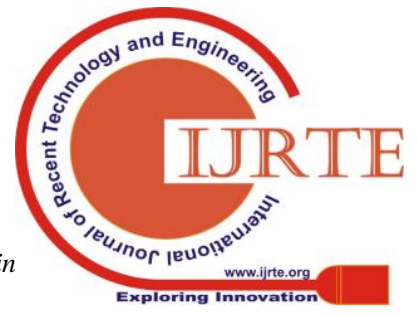

